\title{
SLEEP QUALITY IN PATIENTS WITH ACUTE MYOCARDIAL INFARCTION ${ }^{1}$
}

\author{
Carla Renata Silva Andrechuk², Maria Filomena Ceolim ${ }^{3}$
}

\footnotetext{
${ }^{1}$ Article extracted from the thesis - Sleep, daytime sleepiness and risk for obstructive sleep apnea in patients with acute myocardial infarction, submitted to the ao Programa de Pós-Graduação da Faculdade de Enfermagem da Universidade Estadual de Campinas (Unicamp), 2014. Financed by CAPES/social demand scholarship.

${ }^{2}$ Doctoral student in Health Sciences, Programa de Pós-Graduação da Faculdade de Enfermagem, Unicamp. Campinas, São Paulo, Brazil. E-mail: andrechukma@yahoo.com.br

${ }^{3}$ Ph.D. in Nursing, Associate Professor, Faculdade de Enfermagem, Unicamp. Campinas, São Paulo, Brazil. E-mail: fceolim@ unicamp.br
}

\begin{abstract}
The aim of this study was to describe sleep quality and to identify associated factors in patients hospitalized with acute myocardial infarction. A descriptive and cross-sectional study was conducted with 113 patients (70.8\% men, mean age 59.7 years). An instrument was used for sociodemographic and clinical characterization and the Pittsburgh Sleep Quality Index. Results showed that $71.7 \%$ of participants had poor sleep quality and over $64 \%$ slept six hours or less per night. The presence of diabetes mellitus, depression, and absence of physical activity contributed to increase the final score of the Pittsburgh Sleep Quality Index in about 2.5 points for each variable. The identification of sleep quality and proposals of interventions to improve sleep quality must be included in the actions of nurses in order to reduce harm to patients' health before and after the acute myocardial infarction episode.
\end{abstract}

DESCRIPTORS: Sleep. Myocardial infarction. Nursing.

\section{QUALIDADE DO SONO EM PACIENTES COM INFARTO AGUDO DO MIOCÁRDIO}

RESUMO: Este estudo objetivou descrever a qualidade do sono e identificar fatores associados à mesma em pacientes hospitalizados devido a infarto agudo do miocárdio. Estudo descritivo e transversal em que participaram 113 pacientes (70,8\% homens, média de idade 59,7). Utilizou-se um instrumento para caracterização sociodemográfica e clínica e o Índice de Qualidade do Sono de Pittsburgh. Verificou-se que $71,7 \%$ dos participantes tinham sono de má qualidade e que mais de $64 \%$ dormiam seis horas ou menos por noite. A presença de diabete melito, depressão e a ausência da prática de atividade física contribuíram para aumentar o escore final do Índice de Qualidade do Sono de Pittsburgh em cerca de 2,5 pontos para cada uma destas variáveis. Identificar a qualidade do sono e propor intervenções para sua melhora devem integrar as ações do enfermeiro visando à redução de prejuízos à saúde dos pacientes antes e após episódio de infarto agudo do miocárdio.

DESCRITORES: Sono. Infarto do miocárdio. Enfermagem.

\section{CALIDAD DEL SUEÑO EN PACIENTES CON INFARTO AGUDO DE MIOCARDIO}

RESUMEN: Este estudio tuvo como objetivo describir la calidad del sueño e identificar los factores asociados en pacientes hospitalizados por infarto agudo de miocardio. Estudio descriptivo transversal con 113 pacientes (hombres=70,8\%; edad media=59,7 años). Se utilizó un instrumento para caracterización sociodemográfica y clínica y el Índice de Calidad de Sueño de Pittsburgh. El 71,7\% de los participantes tenía sueño de mala calidad y más del $64 \%$ dormía seis horas o menos por noche. La presencia de diabetes mellitus y depresión y la ausencia de actividad física contribuyeron a aumentar el marcador final del Índice de Calidad de Sueño de Pittsburgh en aproximadamente 2,5 puntos en cada variable. La identificación de la calidad del sueño y propuestas de intervenciones para su mejora deben integrar las acciones de enfermeros para reducir el daño a la salud de los pacientes antes y después del episodio de infarto agudo de miocardio.

DESCRIPTORES: Suenõ. Infarto del miocárdio. Enfermería. 


\section{INTRODUCTION}

In 2011 , there were 82,771 deaths by acute myocardial infarction (AMI) in Brazil. 46.7\% in the southeast. ${ }^{1}$ Data from the USA estimate that there are approximately 525,000 new cases and 190,000 recurring cases of AMI yearly, with a mean age of 64.7 and 72.2 years for men and women, respectively ${ }^{2}$ which shows the magnitude of the disease.

Poor sleep quality and disorders are considered additional risk factors for cardiovascular disease (CVD) and AMI. ${ }^{3-5}$

Many authors point out that changes in the duration of sleep (less than five hours and more than nine hours) are related to an increased risk of developing and/or dying of coronary disease ${ }^{6-8}$ and AMI. ${ }^{9}$ Other studies show that less than six hours of sleep per night, ${ }^{10-12}$ or less than seven and a half hours for diabetic patients, ${ }^{13}$ represents a higher risk for AMI.

In a study conducted in the city of São Paulo, the authors observed that an increased risk for CVD was associated with low sleep efficiency and aging, which shows the relationship between sleep disorders and cardiac disease. ${ }^{14}$

Sleep plays a crucial role in disease prevention and recovery. ${ }^{15}$ Sleep deprivation can cause impairments in cognition, memory, emotional stability and in the regulation of immunological and inflammatory functions, in addition to increase in appetite. ${ }^{16}$ In healthy men, partial sleep deprivation for only five nights was enough to cause venous endothelial dysfunction and disorders in the cardiovascular autonomic control, with a significant increase in sympathetic activity and impairment in blood pressure variability. ${ }^{17}$

In a prospective cohort study, duration of sleep equal to or higher than seven hours, associated with other four lifestyle factors (physical activity, healthy diet, moderate use of alcohol and no smoking) was related to a lower risk of cardiovascular disease. ${ }^{10}$

This study had the aim of describing quality of sleep according to sociodemographic and clinical characteristics in patients who suffered an episode of AMI and identifying factors associated with these individuals' sleep quality.

\section{METHOD}

This was a descriptive, correlational and cross-sectional study, carried out in two units of a teaching hospital, namely the cardiology ward and the coronary unit (COU), from October 2013 until March 2014.

Study participants were 113 subjects who were hospitalized with an AMI diagnosis, with or without ST-segment elevation. Among patients identified with this diagnosis, we excluded those who presented any of the following conditions: previous hospitalization with a discharge date earlier than 30 days; admission to the COU or cardiology ward after 72 hours of hospital admission; decline in clinical status in the first 72 hours that affected the performance of interviews and the answering of instruments.

Sample size was estimated for an investigation with a larger scale concerning sleep quality, daytime sleepiness and risk for sleep apnea in patients with AMI, from which this study was extracted. The proposed methodology was used to calculate sample size for an unpaired t-test, considering a study ${ }^{18}$ in which the group of subjects with improvement in clinical status obtained an average of 7.2 and standard deviation of 4.4 points in the score of the instrument that assessed quality of sleep, and those with declined clinical status obtained an average of 10.3 and standard deviation of 3.8 points, in a proportion of $15 \%$ of subjects with a declining clinical status; significance level of $5 \%$; power of $80 \%$. The calculated sample size was 121 subjects, of which 18 should present decline in clinical status.

The research proposal was approved by the Research Ethics Committee of the authors' institution in 2013, according to CAAE number: 09731112.4.0000.5404. Participants were informed of the study's objectives and signed a Free and Informed Consent Form, according to the requirements of Resolution No. 466/2012 from the National Health Council.

The following instruments were used:

1. Sociodemographic and clinical questionnaire created for the study and previously submitted to content assessment by three experts with well-reputed knowledge in the areas of nursing care for cardiac patients and validation of assessment instruments. The questionnaire has questions for the identification of the patients, socioeconomic profile, health history, information on the current treatment and clinical evolution (improvement or decline) up to discharge. The investigated variables were: gender, age, marital status, education level, family income, current work status, body mass index (BMI), smoking habit, alcohol consumption (possible cardiovascular risk when 
the consumption of ethanol exceeds $30 \mathrm{mg} / \mathrm{dl}$ for men and $15 \mathrm{mg} / \mathrm{dl}$ for women) ${ }_{1}^{19}$ physical activity, waist circumference (possible cardiovascular risk when waist circumference is above $94 \mathrm{~cm}$ for men and $80 \mathrm{~cm}$ for women), ${ }^{20}$ arterial hypertension, hypercholesterolemia, diabetes mellitus, type of AMI and previous AMI.

2. Pittsburgh Sleep Quality Index (PSQI) ${ }^{21}$ to assess subjective quality of sleep in the 30 days previous to current hospitalization, when the individual was at home. The version validated for Brazil, known as PSQI-BR, ${ }^{22}$ was used. This questionnaire has 19 self-administered questions, grouped into seven parts: subjective quality of sleep (question 6), sleep latency (questions 2 and $5 a$ ), duration of sleep (question 4), habitual sleep efficiency (ratio between duration of sleep and time spent in bed) - calculated through the difference between bedtime (question 1) and waking time (question 3), sleep disorders (questions $5 b$ until $5 j$ ), use of sleep medication (question 7) and daytime dysfunction (questions 8 and 9). The scores in these parts vary from 0 to 3 and are added up to produce an overall score, which varies from 0 to 21, with a higher score corresponding to worse quality of sleep. The cut-off point of the overall score is 5 , with scores lower or equal to 5 indicating good quality of sleep, and scores above 5 indicating poor quality of sleep.

The instruments were completed by the researcher through interviews and reviews of medical records for clinical variables, being applied up to 72 hours after hospital admission. The obtained data were codified and typed into an electronic spreadsheet in Microsoft Office Excel® and analyzed with the Statistical Analysis System (SAS) version 9.2, and the Statistical Package for the Social Sciences, version 16.0.

Sociodemographic and clinical data, as well as those referring to sleep quality and characteristics, were analyzed by means of descriptive statistics. The scores obtained in the PSQI-BR were compared according to categorical variables through Mann-Whitney and Kruskal-Wallis tests. Using the final score in the PSQI-BR as dependent and the sociodemographic variables as independent variables, a linear regression model with selection of variables according to the stepwise criteria was produced. Significance was set at 5\% for all analyses.

The test's power ${ }^{23}$ was calculated according to the proposed methodology for the multiple linear regression analysis model.

\section{RESULTS}

In the researched population $(n=113)$, there was a predominance of the male gender, $70.8 \%$. Ages varied from 36 to 88 years, with a mean of 59.7 and standard deviation of 12.3 years. The most frequent characteristics for patients were: married $(76.1 \%)$, with a mean of 5.7 (standard deviation 4.4) years of formal study and mean family income of 3.7 (standard deviation 3.2) minimum wages. Concerning occupation, $60.2 \%$ reported being employed and $39.8 \%$ were retired, unemployed or on leave.

A total of $76.9 \%$ had arterial hypertension, $35.4 \%$ had diabetes mellitus, and $42.5 \%$ hypercholesterolemia. The most frequent diagnosis was AMI with ST-segment elevation, present in $53.1 \%$ of subjects. In $71.7 \%$ of cases, it was the first episode of this event.

As observed, $71.7 \%$ of patients with AMI had frequent poor sleep quality according to the PSQI-BR grade, whereas $62.8 \%$ reported good subjective sleep quality. The mean points obtained in the overall score of the PSQI-BR was 8.1, with a standard deviation of 3.8 and median of 7.0 , which indicates poor sleep quality. A proportion of $64.6 \%$ of patients reported sleeping for six hours or less. Table 1 shows results regarding their habitual sleep characteristics according to answers in the PSQI-BR.

Table 1 - Habitual sleep characteristics in patients with acute myocardial infarction according to answers to the Pittsburgh Sleep Quality Index (PSQI-BR) (n=113). Campinas, São Paulo, Brazil, 2013-2014

\begin{tabular}{lccc}
\hline $\begin{array}{l}\text { Habitual sleep } \\
\text { characteristics }\end{array}$ & Mean & $\begin{array}{c}\text { Standard } \\
\text { deviation }\end{array}$ & Median \\
\hline Bedtime & $23 \mathrm{~h} 13 \mathrm{~min}$ & $83 \mathrm{~min}$ & $22 \mathrm{~h} 00 \mathrm{~min}$ \\
Waking time & 06h07min & $91 \mathrm{~min}$ & 06h00min \\
Sleep latency & $28.6 \mathrm{~min}$ & $25.0 \mathrm{~min}$ & $20.0 \mathrm{~min}$ \\
$\begin{array}{l}\text { Duration of sleep } \\
\text { Habitual sleep }\end{array}$ & $366 \mathrm{~min}$ & $96 \mathrm{~min}$ & $360 \mathrm{~min}$ \\
efficiency & $78.8 \%$ & $22.1 \%$ & $80.0 \%$ \\
\hline
\end{tabular}

Among factors that contributed for the sleep disorder component, $58.4 \%$ reported the need to get up to go to the bathroom and $48.7 \%$ reported waking up in the middle of the night or very early in the morning.

The comparison of the PSQI-BR score according to sociodemographic and clinical variables is on Table 2. 
Table 2 - Descriptive statistics and p-value of comparisons between total scores in the Pittsburgh Sleep Quality Index (PSQI-BR) and variables in patients with acute myocardial infarction $(n=113)$. Campinas, São Paulo, 2013-2014

\begin{tabular}{|c|c|c|c|}
\hline Variables & Median & Mean (SD) & p-value \\
\hline Gender & & & $0.013^{*}$ \\
\hline Male & 7.0 & $7.5(3.7)$ & \\
\hline Female & 10.0 & $9.5(3.9)$ & \\
\hline Age group & & & $0.758^{*}$ \\
\hline Up to 60 years & 7.0 & $8.0(3.9)$ & \\
\hline 60 years or more & 8.0 & $8.2(3.8)$ & \\
\hline Marital status & & & $0.193 \dagger$ \\
\hline Married & 7.0 & $8.1(3.9)$ & \\
\hline Single & 8.0 & $8.4(3.8)$ & \\
\hline Widowed & 10.0 & $10.0(3.1)$ & \\
\hline Separated & 7.0 & $6.5(3.3)$ & \\
\hline Body mass index & & & $0.816^{*}$ \\
\hline Under or equal to $30 \mathrm{~kg} / \mathrm{m}^{2}$ & 7.0 & $8.2(3.8)$ & \\
\hline Over $30 \mathrm{~kg} / \mathrm{m}^{2}$ & 8.0 & $7.9(3.9)$ & \\
\hline Smoking habit & & & $0.745 \dagger$ \\
\hline Non-smoker & 8.5 & $8.2(3.8)$ & \\
\hline Smoker & 7.0 & $7.7(3.5)$ & \\
\hline Ex-smoker & 7.0 & $8.5(4.2)$ & \\
\hline Risk alcohol consumption & & & $0.895^{*}$ \\
\hline Yes & 8.0 & $8.1(3.1)$ & \\
\hline No & 7.0 & $8.1(4.0)$ & \\
\hline Arterial hypertension & & & $0.158^{*}$ \\
\hline Yes & 8.0 & $8.4(3.9)$ & \\
\hline No & 6.5 & $7.1(3.3)$ & \\
\hline Diabetes mellitus & & & $0.023^{*}$ \\
\hline Yes & 10.0 & $9.4(4.6)$ & \\
\hline No & 7.0 & $7.4(3.1)$ & \\
\hline Hypercholesterolemia & & & $0.590^{*}$ \\
\hline Yes & 7.5 & $7.8(3.5)$ & \\
\hline No & 7.0 & $8.3(4.0)$ & \\
\hline Depression & & & $0.028^{*}$ \\
\hline Yes & 10.0 & $10.4(2.6)$ & \\
\hline No & 7.0 & $7.9(3.9)$ & \\
\hline Physical activity practice & & & $0.024^{*}$ \\
\hline Yes & 6.0 & $6.4(3.5)$ & \\
\hline No & 8.0 & $8.5(3.8)$ & \\
\hline Risk waist circumference & & & $0.045^{*}$ \\
\hline Yes $($ man $>94 \mathrm{~cm} ;$ woman $>80 \mathrm{~cm})$ & 8.0 & $8.7(4.0)$ & \\
\hline No & 7.0 & $7.2(3.5)$ & \\
\hline Type of acute myocardial infarction & & & $0.981^{*}$ \\
\hline Without ST elevation & 8.0 & $8.2(4.2)$ & \\
\hline With ST elevation & 7.0 & $8.0(3.5)$ & \\
\hline Previous acute myocardial infarction & & & $0.542^{*}$ \\
\hline Yes & 8.0 & $8.6(4.2)$ & \\
\hline No & 7.0 & $7.9(3.7)$ & \\
\hline
\end{tabular}

Table 3 presents the results of the analysis of multiple linear regression, stepwise model, with the PSQI-BR as dependent variable and sociode- mographic and clinical variables as independent variables. 
Table 3 - Multiple linear regression model for the final score in the Pittsburgh Sleep Quality Index (PSQI-BR). Campinas, São Paulo, Brazil, 2013-2014

\begin{tabular}{lccccc}
\hline \multicolumn{1}{c}{ Factor } & Coefficient & Standard-error & CI 95\%* & p-value & $\mathbf{R}^{2}$ \\
\hline Intercept & 7.4 & 0.5 & $(6.48 ; 8.26)$ & $<0.001$ & 0.17 \\
Diabetes mellitus & 2.6 & 0.7 & $(1.21 ; 4.05)$ & 0.001 & \\
Depression & 2.8 & 1.3 & $(0.31 ; 5.25)$ & 0.027 & \\
Physical activity & 2.5 & 0.9 & $(0.71 ; 4.33)$ & 0.006 & \\
\hline
\end{tabular}

$\mathrm{CI}=$ Confidence interval

The final PSQI-BR score was related to the variables diabetes mellitus, depression and physical activity, according to the following equation: PSQI-BR $=7.4+[2.6 \times$ (diabetes mellitus $)]+[2.8 \times(\mathrm{d}$ epression $)]+[2.5 x$ (Physical activity) $]$, in which the variables diabetes mellitus and depression take on the value 1 when present and the value 0 when absent; the variable physical activity takes on value 0 when present and value 1 when absent. This model explains $17 \%$ of score variability in the PSQI-BR (Table 3).

The test's power for linear regression analysis resulted in the value $99 \%$.

\section{DISCUSSION}

An important finding in this study is that over $60 \%$ of patients had short duration of sleep, with six hours or less, and low sleep efficiency. This puts them in the increased risk group, since previous studies on sleep showed that less than six hours of sleep was associated with cardiovascular disease ${ }^{12,24}$ and $\mathrm{AMI}^{12}$ besides representing a higher risk for women. ${ }^{8}$ Previous studies have also shown long duration of sleep (more than nine hours) as a factor associated with CVD and AMI.-9

Sleep quality is of high interest, because it may be associated with increased risks of many diseases, such as AMI, diabetes mellitus, and

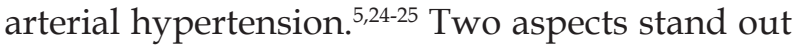
due to their relevance: duration of sleep and sleep disorders, especially fragmentation and problems for falling asleep. ${ }^{26}$

Because of the rhythm of life in modern society, decreases in duration of sleep have become frequent. A study on the American population that uses devices such as cellphones and television close to bedtime showed that $63 \%$ of participants do not have enough sleep. From those, $94 \%$ reported some impact on family life, work, social activities and/or leisure, among others. ${ }^{27}$

Sleep fragmentation, in other words, waking up in the middle of the night or very early in the morning, was reported by $48.7 \%$ of patients with AMI in this study and frequently interfered with sleep quality. A longitudinal study with a monitoring process that lasted 15 years showed that short duration of sleep and sleep disorders were better predictors for coronary disease than duration of sleep alone. ${ }^{26}$

Sleep quality is frequently undervalued by patients, who answer that they have "good" sleep when asked. It was observed that $62.8 \%$ of patients reported good subjective sleep quality when this question was asked directly to them (question 6 of the PSQI-BR), but according to the obtained score, $71.7 \%$ had poor sleep quality, as shown by the mean score of 8.1 points. Many people consider their sleep adequate because their behavioral functioning is intact. ${ }^{28}$

This apparent dissonance highlights the importance of further research on poor sleep quality with more detailed questions or, preferably, with the use of standardized instruments, since a single question can lead to a distorted assessment of sleep quality.

The prevalence of poor sleepers in this study's sample is high and deserves to be carefully observed. Other studies reported similar results: in patients with chronic arterial disease, an author found poor sleep quality in $75.1 \%$ of subjects and a mean score of 8.3 (standard deviation=3.6) points in the PSQI-BR; ${ }^{29}$ patients with atrial fibrillation scored 9.4 points in the PSQI, higher than the control group, which scored 5.8 points. ${ }^{30}$

In short, poor sleep quality among patients with established diseases is more prevalent. In a study conducted in Japan with the population in general, the number of comorbidities was correlated to poor sleep quality and the prevalence of depression was significantly higher among those with a higher number of comorbidities and poor sleep quality, showing that the association among comorbidities can reduce sleep quality. ${ }^{31}$

In this study, scores obtained in the PSQI-BR were significantly higher among women, patients 
with diabetes mellitus, depression and for those who did not engage in physical activities and had increased waist circumference, results similar to those found in another study. ${ }^{9}$ In other studies, the female gender was also associated with poor sleep quality. ${ }^{9,11,29}$

Depression and diabetes mellitus were associated with complaints of short and long durations of sleep in a cross-sectional study with 30,397 participants. ${ }^{9}$ Other authors showed that, for individuals with poor sleep quality, the prevalence of depression increased linearly according to the increase in comorbidities. ${ }^{31}$

The relationship between sleep and diabetes mellitus is well established in literature. A recent study showed that subjects with duration of sleep of under six hours per night presented a $28 \%$ higher risk of developing the disease and, in association with difficulties for falling and keeping asleep, the risk increases to $57 \%$ and $84 \%$, respectively. ${ }^{32}$ Limited hours of sleep and sleep fragmentation were also associated with decreased tolerance for glucose and sensitivity to insulin. ${ }^{25,33}$

The relationship between physical activity and sleep has been explored and it is important to note that it is also considered a factor for decreasing the risk of cardiovascular disease. A sedentary lifestyle is associated with CVDs. ${ }^{34-35}$ Physical training for patients who suffer from cardiac insufficiency, performed for 12 weeks after discharge, improved sleep quality. ${ }^{36} \mathrm{~A}$ follow-up study that lasted between 10 and 14 years showed that physical activity, performed for at least three and a half hours per week, and enough sleep, equal to or over seven hours, reduced the risk of CVD. ${ }^{10}$

The other researched variables did not present statistical significance; however, they can be associated with increased weight gain. ${ }^{37-38}$ Smoking and drinking negatively influence sleep. ${ }^{39-40}$

Results of linear regression for the PSQI-BR score showed that the presence of diabetes mellitus, depression and absence of physical activity contribute for increasing this score, which indicates worse sleep quality.

The cross-sectional design of this study can be considered as a limitation, because it does not enable the assessment of the variables' behavior as time goes on and the inference of causal relationships among them. Sleep patterns were assessed through self-reporting and there was no validation with objective measurements; however, we took precautions when gathering data to use an instrument validated for Brazil (PSQI-BR) and widely used in national and international literatures for 25 years, which supports the results. The sample size that was initially proposed was not reached, as well as the proportion of individuals with decline in clinical status, which was slightly below the goal. This could interfere in the results of association among variables and the regression model. In this regard, we call attention to the power value, which shows the reliability obtained in the linear regression analysis.

\section{CONCLUSION}

Poor sleep quality was found in $71.7 \%$ of researched patients with AMI. Duration of sleep equal to or under six hours was prevalent in the sample and the overall PSQI-BR score was significantly higher in female patients, in those with diabetes mellitus, depression, increased waist circumference and who did not engage in physical activity when compared to male patients, those without diabetes mellitus, depression, increased waist circumference and who engaged in physical activities, respectively. Individuals with diabetes mellitus, depression and who did not engage in physical activities should receive close attention, because these factors significantly contribute for increasing the PSQI-BR score, which indicates poor sleep quality.

Furthermore, aspects such as quality and duration of sleep must be treated by health care workers as risk factors for CVD, which need to be changed or controlled. Therefore, the nurses and the multi-professional team must assess their patients' sleep quality so that they may propose interventions and give instructions to improve sleep quality and/or reduce the effects of poor sleep quality.

\section{REFERENCES}

1. DATASUS. Cadernos de Informação de Saúde [internet] Brasília (DF): SUS; 2011; [acesso 2014 Fev 27]. Available at: www.datasus.gov.br

2. American Heart Association. Heart Disease and Stroke Statistics - 2012 Update: A report from the American Heart Association. Circulation. 2012 Jan; 125(1):e2-220.

3. Boden-Albala B, Roberts ET, Bazil C, Moon Y, Elkind MSV, Tatjana Rundek T, et al. Daytime Sleepiness and risk of stroke and vascular disease: findings from the Northern Manhattan Study (MOMAS). Circ Cardiovasc Qual Outcomes. 2012 Jul; 5(4): 500-7.

4. Knutson KL. Sociodemographic and cultural determinants of sleep deficiency: implications for 
cardiometabolic disease risk. Social Scienc Med. 2013 Feb; 79: 7-15.

5. Grandner MA, Jackson NJ, Pak VM, Gehrman PR. Sleep disturbance is associated with cardiovascular and metabolic disorders. J Sleep Res. 2012 Aug; 21(4):427-33.

6. Cappuccio FP, Cooper D, D'Elia L, Strazzullo P, Miller MA. Sleep duration predicts cardiovascular outcomes: a systematic review and meta-analysis of prospective studies. Eur Heart J. 2011 Jun; 32(12):1484-92.

7. Magee CA, Kritharides L, Attia J, McElduff P, Banks E. Short and long sleep duration are associated with prevalet cardiovascular disease in Australian adults. J Sleep Res. 2012 Aug; 21(4):441-7.

8. Xiao Q, Keadle SK, Hollenbeck AR, Matthews CE. Sleep duration and total and cause-specific mortality in a large US cohort: interrelationships with physical activity, sedentary behavior, and body mass index. Am J Epidemiol. 2014 Nov; 180(10):997-1006.

9. Sabanayagam C, Shankar A. Sleep duration and cardiovascular disease: results from the National Health Interview Survey. Sleep. 2010 Aug; 33(8):1037-42.

10. Hoevenaar-Blom MP, Spijkerman AM, Kromhout D, Verschuren WM. Sufficient sleep duration contributes to lower cardiovascular disease risk in addition to four traditional lifestyle factors: the MORGEN study. Eur J Prev Cardiol. 2014 Nov; 21(11):1367-75.

11. Hung HC, Yang YC, Ou HY, Wu JS, Lu FH, Chang CJ. The association between self-reported sleep quality and overweight in a Chinese population. Obesity (Silver Spring). 2013 Mar; 21(3):486-92.

12. Aggarwal S, Loomba RS, Arora RR, Molnar J. Associations Between Sleep Duration and Prevalence of Cardiovascular Events. Clinical Cardiology. 2013 Nov; 36(11):671-6.

13. Eguchi K, Hoshide S, Ishikawa S, Shimada K, Kario K. Short sleep duration and type 2 diabetes enhance the risk of cardiovascular events in hypertensive patients. Diabetes Res Clin Pract. 2012 Dec; 98(3):518-23.

14. Cintra F, Bittencourt LR, Santos-Silva R, Andersen M, de Paola A, Poyares D et al. The association between the Framingham risk score and sleep: A São Paulo epidemiological sleep study. Sleep Med. 2012 Jun; 13(6):577-82.

15. Monteiro NT, Ceolim MF. Qualidade do sono de idosos no domicílio e na hospitalização. Texto Contexto Enferm [online]. 2014[acesso 2014 Set 18]; 23(2):356-64. Available at http://www.scielo.br/ pdf/tce/v23n2/pt_0104-0707-tce-23-02-00356.pdf

16. Brow LK. Can sleep deprivation studies explain why human adults sleep? Curr Opin Pulm Med. 2012 Nov; 18(6):541-5.
17. Dettoni JL, Consolim-Colombo FM, Drager LF, Rubira MC, Cavasin de Souza SBP, Irigoyen MC, et al. Cardiovascular effects of partial sleep deprivation in healthy volunteers. J Appl Physiol (1985). 2012 Jul;113(2):232-6.

18. Furlani R, Ceolim MF. Sleep quality of women with gynecological and breast cancer. Rev Latino-Am Enfermagem. 2006 Nov-Dec; 14(6): 872-8.

19. Simão AF, Précoma DB, Andrade JP, Correa Filho H, Saraiva JFK, Oliveira GMM. I Cardiovascular Prevention Guideline of the Brazilian Society of Cardiology - Executive Summary. Arq Bras Cardiol. 2014 May;102(5):420-31.

20. Andrade FB, Caldas Junior AF, Kitoko PM, Batista JEM, Andrade TB. Prevalence of overweight and obesity in elderly people from Vitória-ES, Brazil. Ciênc Saúde Coletiva. 2012 Mar; 17(3):749-56.

21. Buysse DJ, Reynolds CF, Monk TH, Berman SR, Kupfer DJ. The Pittsburgh Sleep Quality Index: a new instrument for psychiatric practice and research. Psychiatry Res. 1989 May; 28(2):193-213.

22. Bertolazi AN, Fagondes SC, Hoff LS, Dartora EG, Miozzo ICS, Barba MEF. Validation of the Brazilian portuguese version of the Pittsburgh Sleep Quality Index. Sleep Med. 2010 Jan; 12(1):70-5.

23. Cohen J. Statistical Power Analysis for the Behavioral Sciences. Hillsdale (US): Lawrence Erbaum Associates; 1988.

24. Knutson KL. Sleep duration and cardiometabolic risk: a review of the epidemiologic evidence. Best Pract Res Clin Endocrinol Metab. 2010 Oct; 24(5):73143.

25. Stamatakis KA, Punjabi NM. Effects of sleep fragmentation on glucose metabolism in normal subjects. Chest. 2010 Jan; 137(1):95-101.

26. Chandola T, Ferrie JE, Perski A, Akbaraly T, Marmot MG. The effect of short sleep duration on coronary heart disease risk is greatest among those with sleep disturbance: a prospective study from the Whitehall II cohort. Sleep. 2010 Jun; 33(6):739-44.

27. Gradisar M, Wolfson AR, Harvey AG, Hale L, Rosenberg R, Czeisler CA. The sleep and technology use of Americans: findings from the National Sleep Foundation's 2011 Sleep in America Poll. J Clin Sleep Med. 2013 Dec; 9(12):1291-9.

28. Luyster_FS, Strollo PJ, Zee PC, Walsh JK. Sleep: a health imperative. Sleep. 2012 Jun; 35(6):727-34.

29. Espinheira PFS. Qualidade do sono em portadores de doença arterial coronariana crônica. [tese]. Aracaju (SE): Universidade Federal de Sergipe, Núcleo de Pós-Graduação em Medicina; 2013.

30. Kayrak M, Gul EE, Aribas A, Akilli H, Alibasiç H, Abdulhalikov T, et al. Self-reported sleep quality of patients with atrial fibrillation and the effects of cardioversion on sleep quality. Pacing Clin Electrophysiol. 2013 Jul; 36(7):823-9. 
31. Hayashino Y, Yamazaki S, Takegami M, Nakayama T, Sokejima S, Fukuhara S. Association between number of comorbid conditions, depression, and sleep quality using the Pittsburgh Sleep Quality Index: results from a population-based survey. Sleep Med. 2010 Apr; 11(4):366-71.

32. Cappuccio FP, D’Elia L, Strazzullo P, Miller MA. Quantity and quality of sleep and incidence of type 2 diabetes: a systematic review and meta-analysis. Diabetes Care. 2010 Feb; 33(2):414-20.

33. Buxton OM, Pavlova M, Reid EW, Wang W, Simonson DC, Adler GK. Sleep restriction for 1 week reduces insulin sensitivity in healthy men. Diabetes. 2010 Sep; 59(9):2126-33.

34. Li J, Siegrist J. Physical activity and risk of cardiovascular disease-a meta-analysis of prospective cohort studies. Int J Environ Res Public Health. 2012 Feb; 9(2):391-407.

35. Del Brutto OH, Mera RM, Zambrano M, Del Brutto VJ, Castillo PR. Association between sleep quality and cardiovascular health: a door-to-door survey in rural Ecuador. Environ Health Prev Med. 2014 May; 19(3):234-37.
36. Suna JM, Mudge A, Stewart I, Marquart L, O' Rourke $\mathrm{P}$, Scott A. The effect of a supervised exercise training programme on sleep quality in recently discharged heart failure patients. Eur J Cardiovasc Nurs. 2014 Jun; 14(3):198-205.

37. Jean-Louis G, Williams NJ, Sarpong D, Pandey A, Youngstedt S, Zizi F, Ogedegbe G. Associations between inadequate sleep and obesity in the US adult population: analysis of the national healthinterview survey (1977-2009). BMC Public Health. 2014 Mar; 14(1):290-9.

38. Mozaffarian D, Hao T, Rimm EB, Willett WC, Hu FB. Changes in diet and lifestyle and long-term weight gain in women and men. N Engl J Med. 2011 Jun 23; 364(25):2392-404.

39. Kenney SR, Paves AP, Grimaldi EM, La Brie JW. Sleep quality and alcohol risk in college students: examining the moderating effects of drinking motives. J Am Coll Health. 2014 May; 62(5):301-8.

40. Sabanayagam C, Shankar A. The association between active smoking, smokeless tobacco, secondhand smoke exposure and insufficient sleep. Sleep Med. 2011 Jan; 12(1):7-11. 